\title{
Future teacher's artistic and sports development throughout planning events with scouting elements
}

\author{
LEYSAN R. TUKHVATULLINA ${ }^{1}$, AIGUL A. KHAFIZOVA ${ }^{1}$, TIMUR A. KHALMETOV², GULNAZ R. \\ YUNUSOVA ${ }^{1}$, EKATERINA V. MOKEEVA ${ }^{1}$ \\ ${ }^{1}$ Institute of Psychology and Education, Kazan (Volga region) Federal University, Russian Federation \\ 2Department Tactical Training and Firearms Training, Kazan Law Institute of the MIA of Russia, Russian Federation
}

\begin{abstract}
Present article is aimed to detect students', future primary school pedagogues' knowledge and preparedness to plan extracurricular activities for younger pupils. The given research enables to learn the dynamics of the students' enthusiasm for projecting extracurricular activities, using new components from the Scout experience in their creative work. Leading research methods of a given problem turned to be methods of theoretical analysis of pedagogical, psychological scientific literature; study of advanced pedagogical experience; survey, test task with the principles, methods and elements of Scouting; quantitative and qualitative analysis of results, processing of research results by methods of descriptive statistics. Students at Kazan pedagogical college future primary school teachers participated in the research. The article presents the results of the diagnostics of future teachers in the context of the concepts of "creative self-development", "children's organization", "children's movement", as well as the results of the diagnostics of the readiness to plan and apply extracurricular activities in their work that develop the social competence of younger students Scout Method. The reliability of the research results is provided by: 1) the validity of the initial theoretical regulations and the analysis of the problem; 2) the presented structure of the theoretical and experimental stages of the study; 3 ) the use of theoretical and empirical research methods. The materials presented in the article reflect the dynamics of the pedagogical college students', future primary school teachers, interest and readiness to plan extracurricular activities with the implementation of the children's organization experience, which contribute to the development of creative potential and social activity of students. Practical significance consists in the fact that pedagogues in the educational process may use recommendations on projecting extracurricular activities with applying experience of children's organizations. To detect and develop the pedagogical college students design competence, a number of pedagogical conditions for effective planning of extracurricular activities programs were established: organizational and pedagogical (information; setting goals for the proposed activity; consulting in the process of work); psychological and pedagogical (cooperation; emotional background; support for the initiative and independence of participants); didactic (methodological recommendations; use of ICT; shifting the focus from the teacher activities to the student activities).
\end{abstract}

Keywords: Sport development; Physical education; Creativity; Self-development of the future teacher; Extracurricular activities; Social activity; Scouting.

Cite this article as:

Tukhvatullina, L.R., Khafizova, A.A., Khalmetov, T.A., Yunusova, G.R., \& Mokeeva, E.V. (2021). Future teacher's artistic and sports development throughout planning events with scouting elements. Journal of Human Sport and Exercise, 16(3proc), S1162-S1171. https://doi.org/10.14198/ihse.2021.16.Proc3.32

Corresponding author. Institute of Psychology and Education, Kazan (Volga region) Federal University, Russian Federation.

E-mail: springrain3415@list.ru

Abstract submitted to: Winter Conferences of Sports Science. Costa Blanca Sports Science Events, 22-23 March 2021. Alicante, Spain.

JOURNAL OF HUMAN SPORT \& EXERCISE ISSN 1988-5202.

(c) Faculty of Education. University of Alicante.

doi:10.14198/jhse.2021.16.Proc3.32

S1162

| 2021 | Proc3 | VOLUME 16

C 2021 University of Alicante 


\section{INTRODUCTION}

The research urgency of the issue is determined by the requirements imposed by society to the development of an individual. The 21st century education dictates acquisition of new professional competences to both teachers and students. Modern practical conditions require a teacher capable of social transformation and focused on self-development and social creativity (Zyubina et al., 2019; Khairullina et al., 2020). Future teachers' professional competence depends on their social activity, self-development aspects, formed selfconcept and ideas of their creative potential, which allow stimulating their own resources to overcome nonstandard situations in the workplace and life (Bayanova et al., 2019; Piralova et al., 2020). Future primary school teachers' self-development containing elements of scout movement appears to be one of the sides of personal development that shows the individuality of a future educator. Planning the pedagogical program of extracurricular activities, directed to the improvement of social competences and artistic self-development of students is largely determined by the fact that nowadays the biggest part of resources is focused on science and sport and therefore pedagogical influence of social institutes of Russian culture, art and education on the social side of life has been compromised (Podymov et al., 2019; Gimaliev et al., 2020). The abovementioned determines the relevance of the theoretical proof and a new goal setting in the activities of primary school teachers in planning and application of extracurricular activities with elements of the Scout movement.

The analysis of scientific literature has shown that the consideration of the creative development and social competence issue has a general, declarative nature. In a series of papers, researchers consider certain aspects of social competence and their manifestations in certain fields of social interaction. In the pedagogical literature, there are various approaches to determining social competence (Kuznetsova et al., 2018). One of the approaches is based on the consideration of the social competence concept through a certain system of social knowledge and skills, which is presented in the works of N.V. Veselkova and E.V. Pryamikova (2005), V.N. Kunitsyna (2009). Creative self-development issues of personality are presented in the works of Russian scientists V.I. Andreev (1988), M.A. Shchukina (2015), as well as in the studies of foreign representatives: J.P. Downing (1997), M. Fryer (2008). The combination of the definitions listed above suggests a significant opinion of V.I. Andreev (1988), with his broad view of creativity, needs objective and subjective personal conditions to solve the creative task, for progressively obtaining a unique innovative product of public importance.

Creative development of College students constitutes one of the leading aspects of the student's personality development, which reveals the originality and individuality of the College student. Creative development allows College students to become qualified specialists, adapt oneself to the changing circumstances of the outside world, which requires high imaginative initiative and self-development from future teachers. Nowadays the developing social competencies issue of future teachers and the creative component activation is topical. This process is launched through the design of extracurricular activities either. Consequently, there comes a need for the certain types of extracurricular activities, means, and forms of education to update the imaginative self-development and development of future teachers (Mukhametzyanova et al., 2018). A teacher having an education program in his work facilitates professional job. If a roadmap in the process of education is provided, the teacher monitors and controls the educational result, which gives an opportunity to modify the student's route path in the context of the forthcoming educational work. Contemporary techniques and methods of pedagogy, reflected in the route of education, guarantee awakening of interest and increasing of motivation of the student in passing through the stages of social development while mastering new spiritual values and feelings (Vasilkova \& Vasilkova, 2010; Zhgenti et al., 2018). 
Designing educational programs for extracurricular activities by students at the pedagogical College is essential for their professional activities. It provides an opportunity not only to develop students, but also enables future teachers to explore new methods for presenting current knowledge, skills and abilities. Proper organization of extracurricular activities turns to be the field that enhances the creative potential and competitiveness of the future teacher after graduation. The future teacher learns to apply basic knowledge in non-standard situations, which contributes to his socialization.

\section{METHODOLOGICAL FRAMEWORK}

The article is aimed at identifying the knowledge and readiness of students, future primary school teachers, to design extracurricular activities for younger students. The study allowed us to examine the dynamics of students ' interest in designing extracurricular activities, using new components from the scouting experience in their creative work. The leading methods of this problem research are methods of theoretical analysis of pedagogical and psychological scientific literature; examination of innovative pedagogical experience; questionnaire, test task with the principles, methods and elements of scouting; quantitative and qualitative analysis of results, processing of research results by methods of descriptive statistics. Students at Kazan pedagogical college - future primary school teachers participated in the research.

Nowadays, various children's organizations and movements are involved in pedagogical activities in educational organizations: RSM (Russian schoolchildren movement), young army, the Council of children's organizations of the Republic of Tatarstan, the Council of high school students, the Scout movement, etc.

There are many children's and youth public associations, organizations, associations, and movements in the Republic of Tatarstan. Many of them carry out activities in the direction of additional education, where the pedagogical component is increasingly covered.

Scouting can be called one of the major organizations of the Republic of Tatarstan, Russia and the world. The educational system of scouting is based on the Scouting Method, composed of such elements as: Law and Promise, learning through job, membership system in small groups, symbolic structure, personal growth, life in harmony with nature and support from adults (Bondar, 1992).

Many of the aforementioned elements, taken separately, are used in other forms of education: for example, creative activities, sessions in groups on the program of a charity project, multi-day trips and hikes on nature, and much more. However, in scouting, these various elements are part of the whole and are exploited as a system, which turns scouting into unique pedagogical phenomenon.

Through scouting, children and young people achieve personal progress, achieve their educational goals, learn to work in a team, use and develop their imaginative abilities, taking responsibility for a particular cause. It is important to note that in today's changing world, scouting, constantly keeping up with the time, called for all generations. It corresponds to kids' aspirations and needs, teenagers and youth has chosen this movement, while remaining true to the traditions of the Scout Method.

Be guided by the requirements for future teachers, namely their professional competencies for organizing extracurricular activities according to the Federal state educational standard of secondary vocational education in the specialty 44.02.02 Teaching in primary classes, and the development of children's organizations and movements in country we came up with the idea of making diagnostics of interest in 
extracurricular activities and its creative application in their practice by students of the pedagogical College, based on the experience of children's organizations and movements.

\section{Experimental base of the study}

The experimental base for the research became the State autonomous professional educational institution "Kazan pedagogical College". The study covered 56 people: students of the third-year pedagogical College whose specialty is 44.02 .02 Teaching in primary classes.

\section{Stages of research}

The study was conducted in three stages:

Declarative stage of the research focused on the proposed issue review, determination of the pedagogical College students' initial level of design competence and creative component through the design of events with scouting elements;

- The formative stage of the research aimed at securing the development of design competence in students at the pedagogical College under certain pedagogical circumstances through imaginative design of extracurricular activities using the Scout Method;

- The control stage of the study is to determine the level of design competence and analyse the proposed problem after creative work on designing extracurricular activities by students at the pedagogical College using the Scout Method.

For diagnostics in the declarative and control stages of the study, the questionnaire "Leisure of students in extracurricular time" was developed and used, it updates the students' understanding of the importance of extracurricular activities, personal participation in them, as well as knowledge of children's organizations and their use in the work of a primary school teacher. Together with the survey, College students were offered a test task "Pedagogical work", which includes components of the methodology of V.P. Bespalko (1989), constituting the following classification of test tasks:

- Level 1 test task-performing recognition activities;

- Level 2 test task-work at the reproduction level;

- Level 3 test task-productive creative activity;

- Level 4 test task-work at the level of creative activity.

When analysing the performance of the test task, the General knowledge and creative component of students at the pedagogical College for designing extracurricular activities are assessed. Therefore, if the results in the test task are low, the goal of further work with students at the pedagogical College is to increase the level of design through the formative stage of the research.

The formative stage of the study included three training sessions. The first lesson had informative purposes only. There was an analysis of the test task with a detailed discussion of each item, introduction to concepts of "children's organization" and "children's movement", as well as watching movies about The Russian school movement and Scouting to enhance the artistic component. During this session, students raised questions, discussions and reflections concerning relevance of the work of children's organizations and movements in educational organizations today were conducted.

In the second lesson, there was an analysis of the algorithm for designing an extracurricular event with all participants of the formative stage of the study. The algorithm of the extracurricular event was given on the example of the quest game "Reconnaissance in the zoo", developed and adapted by the scout team of the Kazan city "Yagodnaya Sloboda". 
In the third lesson, students at the pedagogical College were divided into groups. Then they designed an extracurricular event "Greeting the new year's forest" in a creative atmosphere using the above proposed algorithm for constructing an extracurricular class, applying 2-3 elements of the Scout Method to develop social competencies in primary school students, with the further defending of the project at the end of the class.

\section{RESULTS AND DISCUSSION}

\section{Declarative stage of the study}

The survey "Leisure of students in extracurricular activities" was intended to identify an understanding of the significance of extracurricular activities for students at the pedagogical College, knowledge of children's organizations/movements and readiness to use them in their future activities, designing extracurricular activities based on the programs and experience of children's organizations and movements.

The results of the proposed survey at the declarative stage of the study are given below.

One of the suggested questions in the questionnaire sounded: "Do you think that circles/sections are needed for children/schoolchildren/students? Why?" All respondents in the control group (100\%) said that children/schoolchildren/students need circles / sections, and $90.4 \%$ of respondents in the experimental group answered positively to this question. To the question-clarification: "Why do we need circles/sections for students?", the survey participants of control and experimental groups put forward almost identical versions: it helps the student to develop (62.9\% and $61.9 \%$, respectively), develops students' creativity ( $17.1 \%$ and $4.8 \%$, respectively), students deepen their knowledge, skills ( $14.3 \%$ and $28.6 \%$, respectively), an opportunity to do something useful in their time off occur ( $8.6 \%$ and $4.8 \%$, respectively), helps students realize their future profession (2.6\% and $4.8 \%$, respectively). The following answers to this question were also received: students' outlook are expanding, students have the opportunity to focus on the direction they like, students reveal their resource in different activities, participation in circles / sections contribute the student to find himself, a special worldview is formed, health is improved, students become diligent, sociable, active, smart, sociable, organized, etc. In addition, all respondents believe that participation in circles / sections allows students, on the one hand, to distract from educational activities, on the other hand-helps study, develops diligence and discipline.

Analysing the responses of respondents about their participation in various areas of extracurricular/extracurricular activities, the following results were obtained: the control group respondents participating in the activities of clubs/sections covered all areas of extracurricular/extracurricular activities, namely: $68.6 \%$ of the respondents were participants in the artistic direction, which includes dancing, drawing, theatre Studio, music school, beading, origami, etc.; $54.3 \%$ - participants turned out to be closer to sport direction (volleyball, basketball, gymnastics, swimming, football, Boxing, cheerleading, etc.); $11.4 \%$ choose the socio-pedagogical direction (school of leadership, student Council, etc.); $5.7 \%$ choose the natural science, ecological and biological directions, technical creativity; $2.9 \%$ choose the tourist and local history direction. In the experimental group, the respondents choose only three directions: artistic-85.7\%, physical culture and sports- $23.8 \%$, natural science- $4.8 \%$.

Respondents in both the control and experimental groups were finding it hard while replying to the questions about children's organizations and movements. The majority of respondents are unable to distinguish between "organization" and "movement". Moreover, some respondents understand "children's organization" as any organization connected in any way with the education system, for example, as the Municipal Budget 
Establishment "Committee on children and youth Affairs of the Kazan municipality Executive Committee". Beyond that, the majority of respondents included student organizations and movements into the concepts "children's organization" or "children's movement". The responses included such names as the all-Russian public movement "Victory Volunteers", the Regional youth public organization "League of students of the Republic of Tatarstan", and the all-Russian youth public organization "Russian student groups".

Two questions in the questionnaire were aimed at understanding respondents' positive and negative aspects with the participation of students in extracurricular activities.

When analysing the responses of both groups, the following results have been obtained: the respondents consider that extracurricular activities have positive aspects in the activities of students (the control group$97.1 \%$, the experimental group-85.7\%). Among the positive aspects of the control group respondents highlight getting positive emotions (34.3\%), new and useful acquaintances (31.4\%), gaining new knowledge, skills, learning to work in a team, listening to others, respecting others' opinions (22.9\%), all-round creative development and activity (17.1\%). The experimental group identified all-round development and acquisition of new knowledge, skills (33.3\% each), positive emotions (28.6\%), new and useful acquaintances (14.3\%). In addition, the respondents of the control group see more negative aspects of the proposed activity of students than the respondents of the experimental group ( $80 \%$ and $57.1 \%$, respectively). The respondents of both groups emphasized such aspects as: lack of time (25.7\% and $19 \%$, respectively), academic failure (20\% and $14.3 \%$, respectively), students do not like and not interested in proposed activities (17.1\% and $19 \%$, respectively). It is significant to point out that almost half of the experimental group respondents do not see any negative aspects in the students' participation in extracurricular activities (42.9\%).

The final question of the questionnaire was: "List the activities you plan to implement as a primary school teacher with children/students after school hours". We must note that future primary school teachers are committed to conduct extracurricular activities with their classes- $94.3 \%$ and $81 \%$, respectively. But there are also those who do not consider using extracurricular activities in their work $-5.7 \%$ and $19 \%$, respectively. Among the listed events planned to be held by future primary school teachers, cultural and mass activities are topical. For example, trips to museums, theatres, movies, various excursions, thematic holidays (March 8 , New year, knowledge Day, etc.), and more. In most of the responses walks into the woods, environmental actions, events related to a healthy lifestyle, sports, and volunteer movement were mentioned either.

In order to determine the students' understanding of the educational work meaning and to identify their design competence skill level, the test task, developed applying the components of V.P. Bespalko's (1989) methodology in the structure of extracurricular activities context.

Analysing the data of the test task "Educational work", offered to students at the pedagogical College at the declarative stage of the research, the following should be mentioned: the results of the first test task (recognition activities fulfilment) both in the control and experimental groups are at the same level ( $79 \%$ and $91 \%$, respectively). The same situation was among the responses to the second test task (work at the reproduction level) - $98 \%$ and $100 \%$, respectively. In the third and fourth test tasks (productive creative activity and work at the level of creative activity), the control group showed higher results than the experimental group ( $44 \%$ and $33 \%, 44 \%$ and $9 \%$, respectively). We underline that the control group showed better results in practical tasks than in theoretical ones. 


\section{The formative phase of the study}

In the formative stage of the research, in addition to designing an extracurricular event using the Scout Method, the pedagogical College students were offered a task- to design the event on their own in an imaginative way, as well as to conduct self-assessment of their extracurricular event design.

The result of the performance indicators for the extracurricular activities design using the Scout Method by the pedagogical College students showed that two respondents completed independent work by $50 \%$, four respondents-51-60\%, two respondents- $81-90 \%$, and most of the group (13 respondents) coped with the task by $61-80 \%$. There were no results with a high percentage of work performed, namely more than $91 \%$.

Following the results of the work on designing extracurricular activities using the Scout Method, the study participants were asked to assess their own creative activities.

Analysing the findings of self-assessment, we defined the fact that students in their work put high marks on the following statements:

- "The goal was achieved during the project implementation" - 4.67 points out of 5 possible points;

- "You do not regret your time spent on creating a project" - 4.76 points out of 5 possible points;

- "It was interesting to work on the project" - 4.86 points out of 5 possible points;

- " "The time was successfully planned and used to develop the project" - 4.29 points out of 5 possible points;

- "Your educational event was planned in a proper way" - 4.29 points out of 5 possible points;

- "I would like to continue working in this direction" - 4.38 points out of 5 possible points;

- "Satisfaction with the work performed" - 4.67 points out of 5 possible points;

- "I would like to change the work process" - 3.67 points out of 5 possible points.

Apart from that, the study participants answered a number of questions. To the question "What would you change or add to the process of designing an extracurricular event?" test subjects noted that they would have spent more time on this work.

To the question "What did you like during the work?" the following statements were expressed:

- Searching for interesting tasks,

- Working with different information sources,

- Games inventing,

- An event plan drafting,

- Searching for visual materials,

- Development of certificates for participants.

While designing extracurricular activities the pedagogical College students had difficulties in:

- Selecting a project topic,

- Thinking over the event plan,

- Using the Scout Method in the development of the event,

- Calculating the time,

- Content and final part of the event,

- Forcing oneself to work,

- Self-discipline.

The final question: "What did you learn while working on the project?", has shown the following: 
- To make a plan-summary of extracurricular activities,

- To develop and select tasks,

- To work using Internet resources,

- To take into account age characteristics,

- To plan your time,

- To set a goal and achieve it,

- Got acquainted to the Scouting Method and its components integration in extracurricular activities.

\section{Control stage of the study}

In the control stage of the study, the pedagogical College students were offered a questionnaire "Leisure of students in extra-curricular time", focusing on the topic "The volunteer year in Russia", using their social experience of participation in extra-curricular activities with their wards, and a test task "Educational work".

The respondents of the control and experimental groups suggested the following directions of extracurricular activities on the "The volunteer year in Russia" subject: class hours (on such topics as "I am a volunteer", "Peoples of Russia", "Symbols of Russia", etc.) - 39\%, entertainment events (games, quizzes, visiting concerts, expos, theatres, museums, etc.) - $23 \%$ and $39 \%$, respectively, assistance to those in need (WWII veterans, families in difficult situations, the elderly) - 39\% and $4 \%$, respectively, conversations $-10 \%$ and $30 \%$, respectively, charity events ("Week of good", assistance to animals) $-26 \%$ and $9 \%$, respectively, round tables- $6 \%$ and $4 \%$, respectively.

Comparing the answers to the question about visiting circles/sections in the declarative (visiting ever) and control (visiting now) stages of the study, can be said that currently, respondents devote more time to educational and scientific activities: the control group $-85.7 \%$ in the declarative and $52 \%$ in the control stages of the study, the experimental group- $90.5 \%$ and $57 \%$, respectively.

Of these circles/sections listed by respondents $48 \%$ and $65 \%$, respectively, have artistic, $23 \%$ and $22 \%$, respectively - physical culture and sports, $32 \%$ and $9 \%$, respectively, of the socio-pedagogical direction. Natural-scientific, ecological-biological, tourist-regional studies and technical creativity are not covered by students at the pedagogical College during extracurricular time.

To the question "Did you conduct any extracurricular activities with your students? Which ones?" $58 \%$ of the control group respondents answered positively, $32 \%$ - negatively, and all the experimental group respondents, without exception answered "Yes" (100\%).

The following directions of the listed events held by respondents of both groups, were heard: intellectual events (for instance the game "clever heads", the quest "Mathematics-the Queen of Sciences", the literary club "Pochitay-ka", "Novokvantum", classes in physics, the world around us, music, etc.) - $100 \%$ of respondents; events on HLS ("You can't buy health", "We are for HLS!", "Paths of health" , etc.) - $9.7 \%$ of respondents in the control group and $82.6 \%$ of respondents in the experimental group; class hours on various subjects ( $25.8 \%$ and $47.8 \%$, respectively); entertainment events (fairy tales, games, etc.) $-35.5 \%$ and $13 \%$, respectively; sports events (Spartakiada, aerobics, "Sport is life!" etc.) - 9.7\% and 34.8\%, respectively.

When asked "What difficulties did you have when implementing an extra-curricular event for your students?" most of the respondents in the control group highlighted: organizational question (12.9\%), management of the event participants' discipline (9.7\%), explanation of a new topic and the respondent's emotional state (6.5\% each). In the experimental group, the following difficulties were listed: passivity of children (26.1\%), 
organizational moment (21.7\%), and lack of time (17.4\%), explanation of a new topic (13\%). Among the surveyed students at the pedagogical College, there were also those who had no difficulties in implementing extracurricular activities: $48.4 \%$ of the respondents in the control group, and $17.4 \%$ of the respondents in the experimental group. It is possible that the lack of difficulties in implementing extracurricular activities in the respondents of the control group is due to the lack of design competence among the pedagogical College students, or the lack of experience in conducting extracurricular activities by students at the pedagogical College.

When asked "Will you use extracurricular activities in your work with students, focusing on any children's organization/movement? If so, which children's organization / movement would you like to consider as the main course?" the replies results of the control group respondents did not significantly change in comparison with the results of the declarative stage of the research. In the experimental group, the students' interest in applying the experience of a children's organization/movement in their work when designing extracurricular activities has increased by $25.5 \%$.

\section{CONCLUSION}

According to the results of the study, it can be asserted first that students at the pedagogical College have an idea of the variety of extracurricular activities, second that they personally participate in various circles/sections and social events during their studies in educational organizations. It is important to note that the pedagogical College students are not well acquainted with the algorithm of creating a plan-summary of an extracurricular event, which leads to defects and errors while designing and conducting events.

To detect and develop the pedagogical College students design competence, a number of pedagogical conditions for effective planning of extracurricular activities programs were established. Among them:

- Organizational and pedagogical (information; setting goals for the proposed activity; consulting in the process of work);

- Psychological and pedagogical (cooperation; emotional background; support for the initiative and independence of participants);

- Didactic (methodological recommendations; use of ICT; shifting the focus from the teacher activities to the student activities).

At all stages of the study, the effectiveness of the presented pedagogical conditions for imaginative design of extracurricular activities by the pedagogical College students was tested. According to the results of the study, it is concluded that the presented pedagogical conditions implementation makes it possible for the pedagogical College students to design extracurricular activities based on the Scout Method in an imaginative way and to use the experience of the scout organization in future. The research reports the pedagogical College students' dynamics of interest and readiness to design extracurricular activities using the Scout Method in an imaginative way. Future primary school teachers are open to new methods of work, using the experience of children's organizations and movements in their extracurricular activities, understanding all possible positive and negative aspects that may occur with the participation of students involved in such kind of activities.

\section{ACKNOWLEDGMENTS}

The work is performed according to the Russian Government Program of Competitive Growth of Kazan Federal University. 


\section{REFERENCES}

Andreev, V.I. (1988). Dialectics of education and self-education of a creative person. Kazan: Izdatel'stvo Kazanskogo Universiteta.

Bayanova, A.R., Vodenko, K.V., Sizova, Zh.M., Chistyakov, A.A., Prokopiev, A.I., \& Vasbieva, D.G. (2019). A philosophical view of organizational culture in contemporary universities. European Journal of Science and Theology, 15(3), 121-131.

Bespalko, V.P. (1989). Components of pedagogical technologies. Moscow: Pedagogika.

Bondar, L.A. (1992). What is scouting? A book for a scout leader. Geneva: VOSD.

Downing, J.P. (1997). Creative Teaching: Ideas to Boost Student Interest. Englewood: Teacher Ideas Press.

Fryer, M. (2008). Creative teaching and learning in the UK. Braga: Psiquilibrios.

Gimaliev, V.G., Prokopyev, A.I., Vershinin, V.P., Ivanova, M.E., Erkibaeva, G.G., Aytuganova, J.I., \& Alexandrova, N.S. (2020). Public Relations in Organizations in Student View: Accumulator of Management Tools or Formation of Partnership and Friendly Relations. Journal of environmental treatment techniques, 8(4), 1326-1330. https://doi.org/10.47277/JETT/8(4)1230

Khairullina, E.R., Shubovich, M.M., Bogdanova, V.I., Slepneva, E.V., Mashkin, N.A., \& Rodyukova, T.N. (2020). Modern student youth civic identity: Political activity or social responsibility? Opcion, 36(Special Edition 27), 1703-1717.

Kunitsyna, V.N. (2009). Interpersonal communication. St.Petersburg: Piter.

Kuznetsova, N.V., Soloviev, A.A., Botasheva, L.Kh., Lebedev, I.A., Sarkisyan, K.S., Kurdyumov, V.I., Chistyakov, K.A., \& Prokopyev, A.I. (2018). Bachelors safety culture formation in the field of environmental protection. EurAsian Journal of BioSciences, 12(2), 157-166.

Mukhametzyanova, L.Y., Aleksandrova, N.S., Greek, A.D., Zatsepina, M.B., Prokopyev, A.I., \& Gaidamashko, I.V. (2018). Culture-oriented component scientific and methodical support of students' humanitarian training in university. XLinguae, 11(1), 230-241. https://doi.org/10.18355/XL.2018.11.01.19

Piralova, O.F., Gerasimenko, S.A., Kuznetsov, V.V., Popova, O.V., Subbotin, G.V., Kolomyts, O.G., \& Mashkin, N.A. (2020). Gaming Industry Trends in new Generation Specialist Training in University Environment. Journal of Environmental Treatment Techniques, 8(3), 1132-1135.

Podymov, N.A., Nikoghosyan, M.A., Stolyarova, A.N., Narutto, S.V., Mashkin, N.A., Martynenko, S.E., Paznikova, Z.I., \& Varenik, P.K. (2019). University New Educational Reality in Disruptive Technologies Context. Journal of Environmental Treatment Techniques, 7(4), 664-668.

Shchukina, M. A. (2015). Psychology of personal self-development. St.Petersburg: SPbSU.

Vasilkova, T.A. \& Vasilkova, Yu.V. (2010). Social pedagogy. Moscow: KNORUS.

Veselkova, N.V. \& Pryamikova, E.V. (2005). Social competence of growing up. Yekaterinburg: Izdatel'stvo ural'skogo universiteta.

Zhgenti, I.V., Kuznetsova, V.V., Savinov, A.M., Gribova, O.E., Sidyacheva, N.V., \& Prokopyev, A.I. (2018). Modern integration processes influence on educator's professional growth. Espacios, 39(2), 13.

Zyubina, I.A., Dzyubenko, A.I., Borisenko, V.A., Popova, O.V., \& Prokopyev, A.I. (2019). Implicit Linguopragmatic strategies of speech behavior of English-speaking prosecutors. XLinguae, 12(4), 92-102. https://doi.org/10.18355/XL.2019.12.04.08

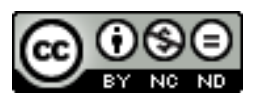

This work is licensed under a Attribution-NonCommercial-NoDerivatives 4.0 International (CC BY-NC-ND 4.0). 